\title{
ANALISIS PONDASI BORED PILE PADA PROYEK JALAN TOL MEDAN- KUALANAMU-TEBING DENGAN METODE ANALITIS DAN METODE ELEMEN HINGGA
}

\section{Baliaan Muhammad Maulana, Roesyanto, Rudi Iskandar}

Universitas Sumatera Utara (USU) Medan Sumatera Utara, Indonesia

Email: baliaanmm@gmail.com, roesyantos@yahoo.com, sipil.s2.usu@gmail.com

\begin{tabular}{l}
\hline INFO ARTIKEL \\
\hline Diterima \\
19 Juni 2021 \\
Direvisi \\
19 Juni 2021 \\
Disetujui \\
21 Juni 2021 \\
\hline Keywords: \\
Carrying Capacity, Drop, \\
Bored pile
\end{tabular}

\begin{abstract}
ABSTRAK
Bored Pile foundation is a solution in the selection of deep foundations with some complex circumstances that do not allow the use of stakes. But in the analysis, there is a difference with the foundation of the stake so that the analysis of the stake can not be applied in bored pile calculations. The purpose of this study is to conduct Bored Pile analysis in the form of analytical support and decrease and element methods up to Plaxis 3D. Based on the results of the analysis, the carrying capacity value of the single Bored Pile obtained from analytical calculations with the O'neil and Reese methods was 511.03 tons, while based on the interpretation of loading tests in the field with the Davisson method is 410 tons, with the Chin method 560 tons and the Mazurkiewichz method is 630 tons. The carrying capacity of the 3D Plaxis analysis with Davisson method is 155 tons, Chin method is 547 tons and mazurkiewichz method is 635 tons. The large drop of Bored Pile analytically by elastic drop method is $56.6 \mathrm{~mm}$, with 3D Plaxis analysis with Medium mesh is $219 \mathrm{~mm}$, while the result of decrease in the field based on loading test data is 36.4 $\mathrm{mm}$. Based on the results of the analysis that has been done, it can be concluded that the ultimate carrying capacity value bored pile based on O'neil and Reese method is greater than the result of loading test interpretation with Davisson method, and the largest value obtained from interpretation of Mazurkiewichz method. As for the results of the decline analysis, the largest decrease that is closest to the results in the field is based on the elastic reduction method.
\end{abstract}

$\begin{array}{ll}\text { How to cite: } & \text { Maulana, Baliaan Muhammad, dkk (2021) Analisis Pondasi Bored Pile pada Proyek Jalan Tol Medan- } \\ & \text { Kualanamu-Tebing dengan Metode Analitis dan Metode Elemen Hingga. Jurnal Syntax Admiration } \\ & 2(6) \text {. https://doi.org/10.46799/jsa.v2i6.257 } \\ \text { E-ISSN: } & 2722-5356 \\ \text { Published by: } & \text { Ridwan Institute }\end{array}$




\begin{tabular}{l}
\hline ABSTRAK \\
Pondasi Bored Pile merupakan solusi dalam pemilihan \\
pondasi dalam dengan beberapa keadaan yang kompleks \\
sehingga tidak memungkinkan penggunaan tiang \\
pancang. Namun dalam analisisnya, terdapat perbedaan \\
dengan pondasi tiang pancang sehingga analisis tiang \\
pancang tidak dapat diaplikasikan dalam perhitungan \\
Bored Pile. Tujuan dari penelitian ini adalah melakukan \\
analisis Bored Pile berupa daya dukung dan penurunan \\
secara analitis dan metode elemen hingga dengan Plaxis \\
3D. Berdasarkan hasil analisis yang dilakukan, nilai daya \\
dukung ultimate Bored Pile tunggal yang didapat dari \\
perhitungan secara analitis dengan metode O'neil dan \\
Reese adalah 511,03 ton, sedangkan berdasarkan \\
interpretasi pengujian pembebanan di lapangan dengan \\
metode Davisson adalah 410 ton, dengan metode Chin \\
560 ton dan metode Mazurkiewichz adalah 630 ton. \\
Besar daya dukung dari hasil analisis Plaxis 3D dengan \\
metode Davisson adalah 155 ton, metode Chin 547 ton \\
dan dengan metode Mazurkiewichz adalah 635 ton. \\
Besar penurunan Bored Pile secara analitis dengan \\
metode penurunan elastis adalah 56,6 mm, dengan \\
analisis Plaxis 3D dengan Mesh medium adalah 219 mm, \\
sedangkan hasil penurunan di lapangan berdasarkan data \\
pengujian pembebanan adalah 36,4 mm. Berdasarkan \\
hasil analisis yang telah dilakukan, dapat disimpulkan \\
bahwa nilai daya dukung ultimate Bored Pile \\
berdasarkan metode O'neil dan Reese lebih besar \\
daripada hasil interpretasi loading test dengan metode \\
Davisson, dan nilai terbesar diperoleh dari interpretasi \\
metode Mazurkiewichz. Sedangkan hasil analisis \\
penurunan, besar penurunan yang paling mendekati hasil \\
di lapangan adalah berdasarkan metode penurunan \\
elastis. \\
Kata Kunci: \\
Baya Dukung, Penurunan pile
\end{tabular}

\section{Pendahuluan}

Dalam fungsinya sebagai pemikul dan penyalur beban konstruksi, suatu pondasi tiang harus mempunyai daya dukung tertentu, penurunan tiang yang terjadi juga harus berada dalam batasan yang dapat diterima. Berbagai persamaan dapat digunakan untuk menganalisis besar daya dukung dan penurunan yang terjadi pada pondasi tiang. (Chandra et al., 2018) menganalisis daya dukung pondasi bored pile pada proyek pembangunan menara listrik transmisi $500 \mathrm{kV}$ Peranap-Perawang. Dalam analisisnya, perhitungan dilakukan menggunakan metode Aoki dan de Alencar, metode Schmertmann dan Notthingham, metode Meyerhof dan metode Sangrelatt. Kesimpulan dari penelitian tersebut adalah metode Aoki dan Alencar lebih kritis dan paling minimum dari ketiga metode lainnya. 
Selain dengan perhitungan secara empiris, salah satu cara memperkirakan besar daya dukung dan penurunan pondasi tiang adalah dengan melakukan analisa elemen hingga. Untuk itu diperlukan masukan berupa parameter kekakuan tanah. namun demikian, parameter ini umumnya tidak terdapat secara langsung dalam laporan uji tanah. Para praktisi geoteknik harus menurunkan parameter ini melalui hasil uji boring log melalui korelasi dengan nilai perlawanan uji konus sondir, qc, atau dengan nilai SPT. (Harsanto et al., 2015) dalam tulisannya menganalisis daya dukung tiang bor (bored pile) pada struktur pylon jembatan Soekarno dengan Plaxis 3D. Hasil dari analisis tersebut diantaranya adalah nilai daya dukung aksial Plaxis 3D lebih kecil daripada daya dukung aksial statis dengan selisih persentase sebesar 13,775\%. Settlement Plaxis 3D lebih kecil daripada settlement statis dengan selisih persentase sebesar 6,02.

Seringkali perkiraan penurunan yang di dapat dari hasil permodelan elemen ini ternyata kemudian menyimpang bila dibandingkan dengan hasil uji statik pembebanan tiang (static pile loading test). Untuk itu penulis mencoba melakukan penelitian parameter nilai kekakuan tanah ini melakukan analisis hasil uji beban statik tiang bor. Adapun tujuan dari penelitian ini adalah menganalisis besarnya daya dukung dan pondasi bored pile pada proyek Jalan Tol Medan-Kuala Namu-Tebing Tinggi secara empiris berdasarkan data SPT dan hasil loading test dan metode elemen hingga mengunakan Plaxis 3D. Dari hasil analisis yang dilakukan dapat dilihat bahwa perhitungan metode mana yang akan memberikan hasil paling mendekati kondisi di lapangan.

\section{Metode Penelitian}

Analisis dalam penelitian ini dilakukan menggunakan dua metode yaitu metode analitis dan metode elemen hingga. Analisis dilakukan dalam menghitung daya dukung dan penurunan pondasi bored pile pada proyek jalan tol Medan-Kualanamu-Tebing Tinggi. Metode analitis yang dilakukan adalah dengan melakukan perhitungan daya dukung bored pile dengan persamaan (Fuad, 2005). Sedangkan perhitungan penurunan dengan persamaan penurunan elastis.

Analisis metode elemen hingga dilakukan dengan membuat pemodelan pada Plaxis 3D. Pemodelan dilakukan dengan menginterpretasikan kondisi di lapangan ke dalam Plaxis. Interpretasi yang dilakukan merupakan sifat material dan proses pembebanan yang dilakukan saat pengujian loading test di lapangan.

Analisis dilakukan menggunakan data teknis bored pile dan hasil pengujian tanah dari pengujian bor mesin berupa data SPT dan karakteritik tanah pada proyek tersebut. Selain itu, sebagai pembanding kondisi sebenarnya digunakan data loading test yang dilakukan di lapangan untuk membandingkan hasil nilai perhitungan terhadap pengujian yang dilakukan di lapangan sehingga dapat disimpulkan keakuratan perhitungan tersebut.

\section{Hasil dan Pembahasan}

\section{Daya Dukung dan Penurunan Bored Pile Berdasarkan Data SPT}

Perhitungan daya dukung bored pile berdasarkan Data SPT dilakukan menggunakan persamaan (Jusi, 2015) Adapun perhitunganya adalah sebagai berikut. 
Analisis Pondasi Bored Pile pada Proyek Jalan Tol Medan-Kualanamu-Tebing dengan Metode Analitis dan Metode Elemen Hingga

Diameter tiang (D) : $1 \mathrm{~m}$

Luas tiang $\left(\mathrm{A}_{\mathrm{b}}\right) \quad: 0,785 \mathrm{~m}^{2}$

Keliling tiang $\left(\mathrm{P}_{\mathrm{i}}\right): 3,14 \mathrm{~m}$

Panjang tiang (L) : $15 \mathrm{~m}$

\section{Tabel 1}

Parameter Tanah yang Digunakan Sebagai Bahan Perhitungan

\begin{tabular}{ccccc}
\hline No & Kedalaman & Tebal Lapisan $(\mathrm{m})$ & $\mathrm{N}_{60}$ rata-rata & $\gamma_{\text {sat }}\left(\mathrm{kN} / \mathrm{m}^{3}\right)$ \\
\hline 1 & $0 \mathrm{~m}-2 \mathrm{~m}$ & 2 & 3 & 16 \\
\hline 2 & $2 \mathrm{~m}-6,6 \mathrm{~m}$ & 4,6 & 9 & 16,5 \\
\hline 3 & $6,6 \mathrm{~m}-15 \mathrm{~m}$ & 8,4 & 60 & 17,8 \\
\hline
\end{tabular}

a. Daya dukung ujung bored pile

Daya dukung ujung bored pile dihitung dengan persamaan berikut ini.

$\mathrm{Q}_{\mathrm{b}}=\mathrm{A}_{\mathrm{b}} \times \mathrm{f}_{\mathrm{b}}$

$\mathrm{f}_{\mathrm{b}}=0,6 \sigma_{r} N_{60} \leq 4500 \mathrm{kPa}$

dimana, $\mathrm{Ab}=$ Luas dasar bored pile $\left(\mathrm{m}^{2}\right), \mathrm{f}_{\mathrm{b}}=$ Tahanan ujung neto persatuan luas $(\mathrm{kPa}), \mathrm{N} 60=$ Nilai $\mathrm{N}-\mathrm{SPT}$ rata-rata antara ujung bawah tiang bor sampai $2 \mathrm{~d}_{\mathrm{b}} \mathrm{di}$ bawahnya, tidak perlu dikoreksi terhadap overburden, $\mathrm{d}_{b}=$ diameter ujung bawah tiang bor $(\mathrm{m}), \sigma_{r}=$ tegangan referensi $=100 \mathrm{kPa}$

maka,

$\mathrm{f}_{\mathrm{b}} \quad=0,6(100 \mathrm{kPa})(60) \leq 4500 \mathrm{kPa}$

$=3.600 \mathrm{kPa} \leq 4500 \mathrm{kPa}$

Maka selanjutnya dihitung daya dukung ujung bored pile dengan persamaan berikut.

$\mathrm{Q}_{\mathrm{b}} \quad=0.785 \mathrm{~m}^{2} .3 .600 \mathrm{kPa}=2.826 \mathrm{kN}$

b. Daya dukung selimut tiang

$\mathrm{Q}_{\mathrm{s}}=\mathrm{f}_{\mathrm{s}} \cdot \mathrm{A}_{\mathrm{s}}$

$\mathrm{f}_{\mathrm{s}}=\beta \sigma_{r^{\prime}}$

dimana, $\mathrm{f}_{\mathrm{s}}=$ daya dukung selimut $\left(\mathrm{kN} / \mathrm{m}^{2}\right), \sigma_{r^{\prime}}=$ tekanan overburden di tengahtengah lapidan tanah $\left(\mathrm{kN} / \mathrm{m}^{2}\right), \delta=$ sudut gesek antara tanah dan tiang (derajat)

Kefisien $\beta$ juga dapat dihitung dengan menggunakan persamaan yang disarankan oleh O’Neil dan Reese (1989):

$\beta=1,5-0,135 \sqrt{\frac{z}{d_{r}}}$

dengan $0,25 \leq \beta \leq 1,2, z=$ kedalaman di tengah-tengah lapisan tanah (m)

Bila lebar referensi $d_{r}=300 \mathrm{~mm}$ disubsitusikan ke persamaan diatas menjadi:

$\beta=1,5-0,245 \sqrt{z}$

Jika $\mathrm{N}_{60} \leq 15$, maka $\beta$ dalam persamaan diatas dikalikan dengan $\mathrm{N}_{60} / 15$ atau 
$\beta=N_{60} / 15(1,5-0,245 \sqrt{z})$

Beberapa nilai $\beta$ untuk tanah non kohesif yang disarankan oleh Reese dkk (2006):

1) Untuk pasir: $\beta=0,25$, jika $\mathrm{z}>26,14 \mathrm{~m}$

2) Untuk pasir yang banyak mengandung kerikil: $\beta=2-0,15 z^{0,75}$ dengan $0,25 \leq \beta \leq 1,8$

3) Untuk pasir berkerikil atau kerikil: : $\beta=0,25$, jika $\mathrm{z}>26,5 \mathrm{~m}$

Maka,

Untuk kedalaman $0-2 \mathrm{~m}, \mathrm{~N}_{60} \leq 15$, maka $\beta$ adalah

$\beta=\frac{3}{15}(1,5-0,245 \sqrt{1})=0,251$

Untuk kedalaman $2-6,6 \mathrm{mN}_{60} \leq 15$, maka $\beta$ adalah

$\beta=\frac{9}{15}(1,5-0,245 \sqrt{2,3})=0,67$

Untuk kedalaman 6,6-15m, $\mathrm{N}_{60} \geq 15$, maka $\beta$ adalah

$\beta=1,5-0,245 \sqrt{4,2}=0,99$

Tabel 2

Perhitungan Daya Dukung Selimut Bored Pile

\begin{tabular}{ccccc}
\hline $\begin{array}{c}\text { Kedalaman } \\
(\mathrm{m})\end{array}$ & $\begin{array}{c}\mathrm{A}_{\mathrm{s}} \\
\left(\mathrm{m}^{2}\right)\end{array}$ & $\begin{array}{c}\text { Tekanan } \\
\text { Overburden } \\
\text { Efektif } \sigma_{r^{\prime}} \\
\left(\mathrm{kN} / \mathrm{m}^{2}\right)\end{array}$ & $\begin{array}{c}\sigma_{r^{\prime}} \text { rata-rata } \\
\left(\mathrm{kN} / \mathrm{m}^{2}\right)\end{array}$ & $\mathrm{Q}_{\mathrm{s}}(\mathrm{kN})$ \\
\hline 2 & 6,28 & 12,4 & 6,2 & 9,77 \\
\hline 6,6 & 14,44 & 43,22 & 27,81 & 269,06 \\
\hline 15 & 26,37 & 110,42 & 76,82 & 2005,48 \\
\hline
\end{tabular}

Maka perhitungan daya dukung selimut bored pile adalah,

$\mathrm{Q}_{\mathrm{s}}=2.284,32 \mathrm{kN}$

Sehingga daya dukung ultimate dan daya dukung ijin bore pile berdasarkan nilai NSPT adalah:

$\mathrm{Q}_{\mathrm{u}}=2.826 \mathrm{kN}+2.284,32 \mathrm{kN}=5.110,3 \mathrm{kN}=511,03$ ton

Perhitungan penurunan bored pile dilakukan menggunakan persamaan penurunan elastis. Adapun tahapan perhitungannya adalah sebagai berikut:

$$
\mathrm{S}=\mathrm{Se}_{(1)}+\mathrm{Se}_{(2)}+\mathrm{Se}_{(3)}
$$

Dengan, $S$ = penurunan total (m), $\mathrm{Se}(1)=$ penurunan elastis dari tiang $(\mathrm{m}), \mathrm{Se}(2)$ = penurunan tiang yang disebabkan oleh beban di ujung Tiang $(\mathrm{cm}), \operatorname{Se}(3)=$ penurunan tiang yang disebabkan oleh beban di sepanjang batang tiang (m)

$$
\mathrm{Se}_{(1)}=\frac{(\mathrm{Qwp}+\xi \mathrm{Qws}) \cdot \mathrm{L}}{\text { Ap.Ep }}
$$


Analisis Pondasi Bored Pile pada Proyek Jalan Tol Medan-Kualanamu-Tebing dengan Metode Analitis dan Metode Elemen Hingga

$$
\begin{aligned}
\mathrm{Se}_{(2)} & =\frac{\text { Qwp.Cp }}{\text { D. qp }} \\
\mathrm{Se}_{(3)} & =\frac{\text { Qws.Cs }}{\text { L. qp }}
\end{aligned}
$$

Dimana, $\mathrm{Q}_{\mathrm{wp}}=$ daya dukung total tiang dikurangi daya dukung friction $(\mathrm{kN})$, Qws= daya dukung friction $(\mathrm{kN}), \mathrm{Ap}=$ luas penampang tiang pancang $\left(\mathrm{m}^{2}\right), \mathrm{L}=$ panjang tiang pancang $(\mathrm{m}), \mathrm{Ep}=$ modulus elastisitas dari bahan tiang $\left(\mathrm{kN} / \mathrm{m}^{2}\right)$, $=$ koefisien dari skin friction, ambil $0,67, \mathrm{D}=$ diameter tiang $(\mathrm{m}), \mathrm{q}_{\mathrm{p}}=$ daya dukung ultimit $(\mathrm{kN}), \mathrm{Cp}=$ koefisien empiris, ambil 0,18 (Tabel 4), Cs= konstanta Empiris.

$$
\mathrm{Cs}=(0,93+0,16 \sqrt{\mathrm{L} / \mathrm{D}}) \cdot \mathrm{C}_{\mathrm{p}} \text {. }
$$

\section{Tabel 3}

Nilai Koefisien Empiris $\left(C_{p}\right)$ (Das, 1995)

\begin{tabular}{lll}
\hline \multicolumn{1}{c}{ Tipe Tanah } & Tiang Pancang & Tiang Bor \\
\hline $\begin{array}{l}\text { Sand (dense to } \\
\text { loose) }\end{array}$ & $0,02-0,04$ & $0,09-0,18$ \\
\hline Clay (stiff to soft) & $0,02-0,03$ & $0,03-0,06$ \\
\hline Silt (dense to loose) & $0,03-0,05$ & $0,09-0,12$ \\
\hline
\end{tabular}

Maka perhitungan penurunan bored pile adalah sebagai berikut:

1. Penurunan elastis

$$
\mathrm{S}_{\mathrm{e}(1)}=\frac{(2.826 \mathrm{kN}+0,67 \times 2.284,32 \mathrm{kN}) 15}{0,785 \mathrm{~m}^{2} \times 21410000 \mathrm{kN} / \mathrm{m}^{2}}=0,0038 \mathrm{~m}=3,8 \mathrm{~mm}
$$

2. Penurunan tiang yang disebabkan oleh bebab di ujung tiang

$$
\mathrm{S}_{\mathrm{e}(2)}=\frac{2.826 \mathrm{kN} \times 0,09}{1 \mathrm{~m} \times 5.110,3 \mathrm{kN}}=0,049 \mathrm{~m}=49 \mathrm{~mm}
$$

3. Penurunan tiang yang disebabkan oleh beban di sepanjang batang tiang

$\mathrm{C}_{\mathrm{s}}=(0,93+0,16 \sqrt{15 / 1}) \times 0,09=0,13$

$\mathrm{S}_{\mathrm{e}(3)}=\frac{2.284,32 \mathrm{kN} \times 0,13}{15 \mathrm{~m} \times 5.110,3 \mathrm{kN}}=0,0038 \mathrm{~m}=3,8 \mathrm{~mm}$

Maka total penurunan tiang tunggal adalah $\mathrm{S}=(3,8+49+3,8) \mathrm{mm}=56,6 \mathrm{~mm}$

\section{Perhitugan Daya Dukung Bored Pile Berdasarkan Data Loading Test}

Perhitungan daya dukung bored pile berdasarkan data loading test dilakukan menggunakan data pengujian pembeban yang telah dilakukan di

\begin{tabular}{|c|c|c|c|c|c|}
\hline No urut & Siklus & Beban (\%) & $\begin{array}{l}\text { Beban uji } \\
\text { (ton) }\end{array}$ & $\begin{array}{c}\text { Penurunan } \\
(\mathbf{m m})\end{array}$ & $\begin{array}{c}\text { Waktu } \\
\text { (jam) }\end{array}$ \\
\hline 1 & \multirow{4}{*}{1} & 0 & 0 & 0 & 0 \\
\hline 2 & & 25 & 75 & 1 & 0,25 \\
\hline 3 & & 50 & 150 & 2,5 & 1,5 \\
\hline 4 & & 25 & 75 & 2,3 & 1,8 \\
\hline
\end{tabular}
lapangan. Data tersebut disajikan pada Tabel 4. Perhitungan dilakukan dengan metode interpretasi Davisson, Mazurkiewich dan Chin.

\section{Tabel 4}

Hasil Loading Test Di Lapangan 


\begin{tabular}{|c|c|c|c|c|c|}
\hline No urut & Siklus & Beban (\%) & $\begin{array}{c}\text { Beban uji } \\
\text { (ton) }\end{array}$ & $\begin{array}{c}\text { Penurunan } \\
(\mathbf{m m})\end{array}$ & $\begin{array}{c}\text { Waktu } \\
\text { (jam) }\end{array}$ \\
\hline 5 & & 0 & 0 & 2 & 2 \\
\hline 6 & \multirow{6}{*}{2} & 50 & 150 & 2,4 & 3 \\
\hline 7 & & 75 & 225 & 4 & 3,8 \\
\hline 8 & & 100 & 300 & 7,5 & 5 \\
\hline 9 & & 75 & 225 & 7,3 & 6 \\
\hline 10 & & 50 & 150 & 7 & 6,2 \\
\hline 11 & & 0 & 0 & 5,8 & 6,5 \\
\hline 12 & \multirow{8}{*}{3} & 50 & 150 & 7 & 7,2 \\
\hline 13 & & 100 & 300 & 8 & 7,8 \\
\hline 14 & & 125 & 375 & 10,3 & 8 \\
\hline 15 & & 150 & 450 & 15,5 & 9 \\
\hline 16 & & 125 & 375 & 15,1 & 10,2 \\
\hline 17 & & 100 & 300 & 15 & 10,6 \\
\hline 18 & & 50 & 150 & 14 & 11 \\
\hline 19 & & 0 & 0 & 13,8 & 11,4 \\
\hline 20 & \multirow{9}{*}{4} & 50 & 150 & 14,2 & 12 \\
\hline 21 & & 100 & 300 & 15 & 12,3 \\
\hline 22 & & 150 & 450 & 17,5 & 12,8 \\
\hline 23 & & 175 & 525 & 24 & 13,5 \\
\hline 24 & & 200 & 600 & 36,4 & 14 \\
\hline 25 & & 150 & 450 & 36,1 & 25,6 \\
\hline 26 & & 100 & 300 & 35,8 & 26,8 \\
\hline 27 & & 50 & 150 & 35,2 & 28 \\
\hline 28 & & 0 & 0 & 32,71 & 31 \\
\hline
\end{tabular}

1. Metode Davisson (1972)

Perhitungan daya dukung aksial bored pile berdasarkan metode Davisson adalah sebagai berikut.

Diameter tiang $\quad=1 \mathrm{~m}$

Panjang tiang $\quad=15 \mathrm{~m}$

Luas tiang $\quad=0,785 \mathrm{~m}^{2}$

Beban rencana $\quad=300$ ton

Beban uji $\quad=600$ ton

f'c $\quad=20,75 \mathrm{MPa}$

$\mathrm{E}=4700 \sqrt{20,75}=21409,52 \mathrm{MPa}=2.140 .952 \mathrm{ton} / \mathrm{m}^{2}$

$\Delta=\frac{300 \text { ton } \times 15 \mathrm{~m}}{2140952 \text { ton } / \mathrm{m}^{2} \times 0,785 \mathrm{~m}^{2}}=0,005355 \mathrm{~m}=5,355 \mathrm{~mm}$

$\mathrm{X}=0,15+39,37 / 120 \mathrm{inch}=8,483 \mathrm{~mm}$ 
Analisis Pondasi Bored Pile pada Proyek Jalan Tol Medan-Kualanamu-Tebing dengan Metode Analitis dan Metode Elemen Hingga

Adapun hasil perhitungan penurunan yang terjadi pada setiap pembebanan disajikan pada Tabel 5. Hasil penggambaran grafik berdasarkan metode Davisson dapat dilihat pada Gambar 1 dibawah ini.

Tabel 5

Perhitungan Penurunan yang Terjadi pada Setiap Pembebanan

\begin{tabular}{cccc}
$\begin{array}{c}\text { Beban } \\
\text { (ton) }\end{array}$ & $\begin{array}{c}\text { Penurunan } \\
\text { maksimum } \\
(\mathbf{m m})\end{array}$ & $\Delta(\mathbf{m m})$ & $\Delta+\mathbf{x}(\mathbf{m m})$ \\
\hline 0 & 0 & 0 & 8,48333783 \\
\hline 75 & 0,79 & 0,66938497 & 9,1527228 \\
\hline 150 & 2,26 & 1,33876994 & 9,82210777 \\
\hline 300 & 7,01 & 2,67753988 & 11,1608777 \\
\hline 450 & 15,5 & 4,01630982 & 12,4996477 \\
\hline 600 & 36,4 & 5,35507977 & 13,8384176 \\
\hline & & &
\end{tabular}

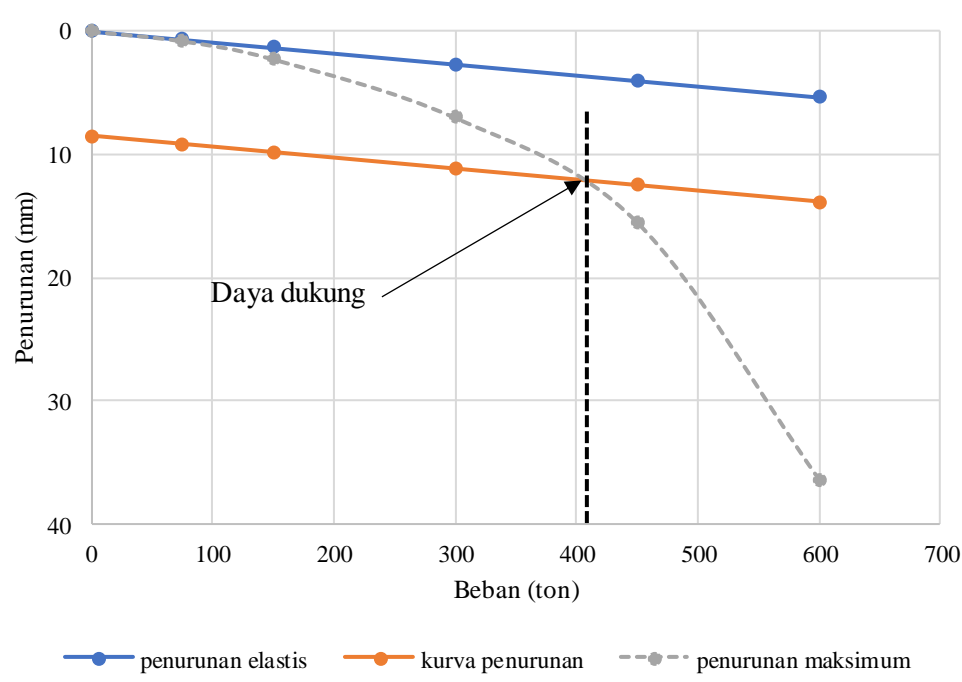

\section{Gambar 1 Grafik hasil perhitungan daya dukung dengan metode Davisson}

Berdasarkan Gambar 1 dapat disimpulkan bahwa daya dukung bored pile berdasarkan hasil pengujian loading test dengan menggunakan metode Davisson adalah 410 ton.

2. Metode Chin

Interpretasi dengan metode Chin (1971) disajikan pada Tabel 7 berikut.

Tabel 6

Perhitungan beban-penurunan metode Chin

\begin{tabular}{ccccccc}
\hline $\begin{array}{c}\text { Penuruna } \\
\mathbf{n}(\mathbf{m m})\end{array}$ & $\begin{array}{c}\text { Beba } \\
\mathbf{n} \\
\text { (ton) }\end{array}$ & $\begin{array}{c}\text { Penurunan/beba } \\
\mathbf{n}\end{array}$ & $\mathbf{S}(\mathbf{x})$ & $\mathbf{S} / \mathbf{Q}(\mathbf{y})$ & $\mathbf{X}^{\mathbf{2}}$ & $\mathbf{X Y}$ \\
\hline 0 & 0 & 0,000 & 0 & 0 & 0,000 & 0 \\
\hline 2,26 & 150 & 0,015 & 2,26 & 0,015 & 5,108 & $\begin{array}{c}0,0340 \\
5\end{array}$ \\
\hline
\end{tabular}




\begin{tabular}{ccccccc}
\hline $\begin{array}{c}\text { Penuruna } \\
\mathbf{n}(\mathbf{m m})\end{array}$ & $\begin{array}{c}\text { Beba } \\
\mathbf{n} \\
\text { (ton) }\end{array}$ & $\begin{array}{c}\text { Penurunan/beba } \\
\mathbf{n}\end{array}$ & $\mathbf{S}(\mathbf{x})$ & $\mathbf{S} / \mathbf{Q}(\mathbf{y})$ & $\mathbf{X}^{\mathbf{2}}$ & $\mathbf{X Y}$ \\
\hline 3,78 & 225 & 0,017 & 3,78 & 0,017 & 14,288 & 0,0635 \\
\hline 7,01 & 300 & 0,023 & 7,01 & 0,023 & 49,140 & 0,1638 \\
\hline 15,45 & 375 & 0,041 & 15,45 & 0,041 & 238,703 & $\begin{array}{c}0,6365 \\
4\end{array}$ \\
\hline 15,5 & 450 & 0,034 & 15,5 & 0,034 & 240,250 & $\begin{array}{c}0,5338 \\
9\end{array}$ \\
\hline 24,55 & 525 & 0,047 & 24,55 & 0,047 & 602,703 & 1,148 \\
\hline 36,4 & 600 & 0,061 & 36,4 & 0,061 & 1324,960 & $\begin{array}{c}2,2082 \\
7\end{array}$ \\
\hline & & & 104,9 & $\begin{array}{c}0,23830634 \\
9\end{array}$ & $\begin{array}{c}2475,151 \\
1\end{array}$ & $\begin{array}{c}4,7880 \\
6\end{array}$ \\
\hline
\end{tabular}

Regresi linier:

a $\quad=\frac{\left(\Sigma y \cdot \Sigma x^{2}\right)-(\Sigma x \cdot \Sigma x y)}{n \cdot \Sigma x^{2}-(\Sigma x)^{2}}=0,0099$

b $\quad=\frac{n \cdot \Sigma x y-\Sigma x \cdot \Sigma y}{n \cdot \Sigma x^{2}-(\Sigma x)^{2}}=0,0015$

diperoleh persamaan garis lurus: $y=0,0015 x+0,0099$

Hasil regresi linier tersebut disajikan pada grafik yang dimuat pada Gambar 4.5.

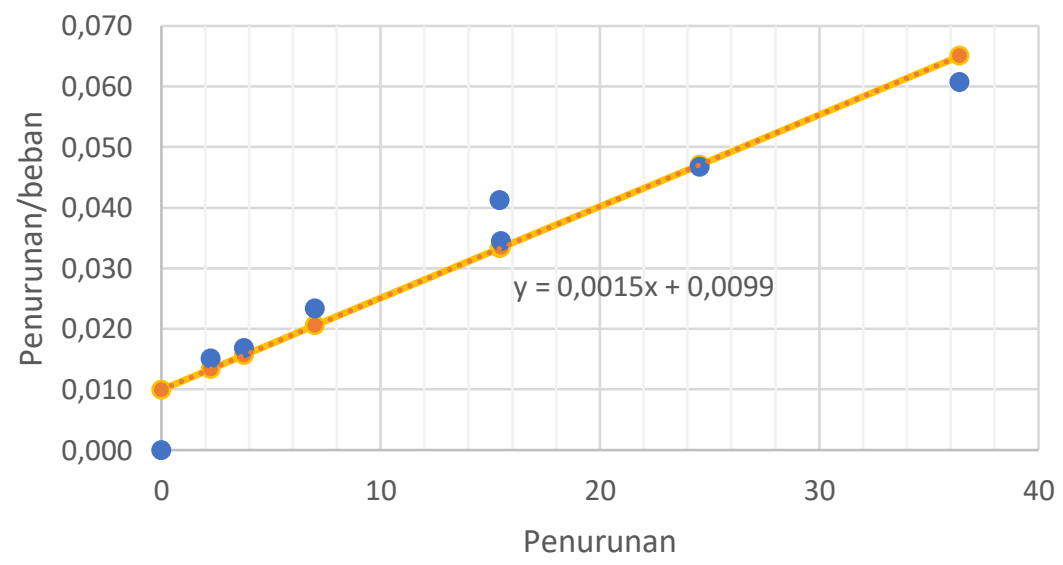

Gambar 2 Grafik hubungan beban-penurunan dengan metode Chin

Besar daya dukung ultimate dengan metode Chin dihitung dengan cara berikut:

$\mathrm{y}=0,0015(36,4)+0,0099=0,065$

$\mathrm{y}=\mathrm{S} / \mathrm{Q}$

$\mathrm{Q}=\frac{36,4}{0,065}=559,89 \approx 560$ ton

$\mathrm{Q}_{\mathrm{ijin}}=560 / 2=280$ ton

Jadi, dengan metode Chin didapatkan daya dukung ultimate tiang bor sebesar 560 ton. 
Analisis Pondasi Bored Pile pada Proyek Jalan Tol Medan-Kualanamu-Tebing dengan Metode Analitis dan Metode Elemen Hingga

3. Metode Mazurkiewich

Interpretasi dengan metode Mazurkiewichz dilakukan dengan menggunakan grafik hubungan beban dan penurunan. Nilai yang akan digunakan dalam grafik disajikan pada Tabel 7.

Tabel 7

Perhitungan beban-penurunan metode Mazurkiewicz

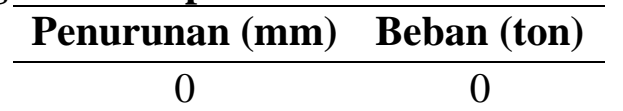

$2,26 \quad 150$

$7,01 \quad 300$

$15,50 \quad 450$

$36,40 \quad 600$

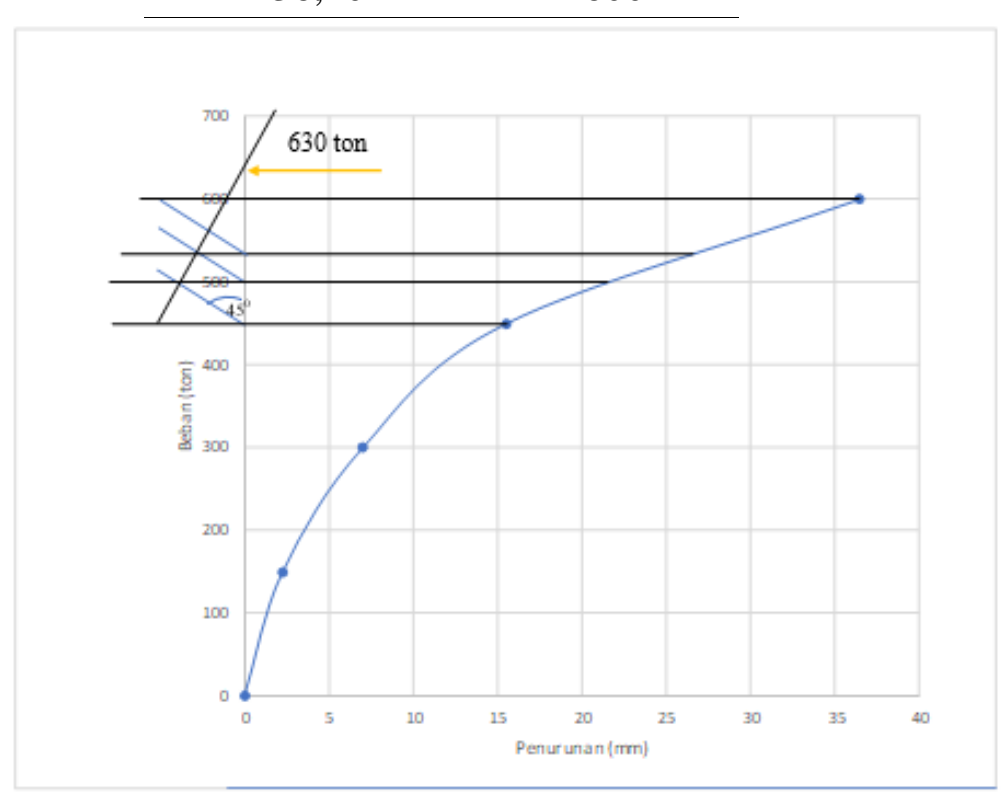

Gambar 3

Daya dukung ultimate dengan metode Mazurkiewicz

Berdasarkan Gambar 3, didapatkan daya dukung ultimate tiang bor adalah 630 ton dengan metode Mazurkiewicz.

3. Analisis Plaxis 3D

Perhitungan daya dukung dan penurunan bored pile dengan Plaxis 3D dilakukan dengan membuat pemodelan konstruksi bored pile sebagai interpretasi keadaan di lapangan. Pada analisis ini pemodelan awal dilakukan dengan menentukan project properties yang akan digunakan pada Plaxis. Pada tools ini pengguna diarahkan untuk memilih jumlah titik nodal, satuan dan model yang akan digunakan. Adapun pengaturan project yang dipilih dapat dilihat pada Gambar 4. 


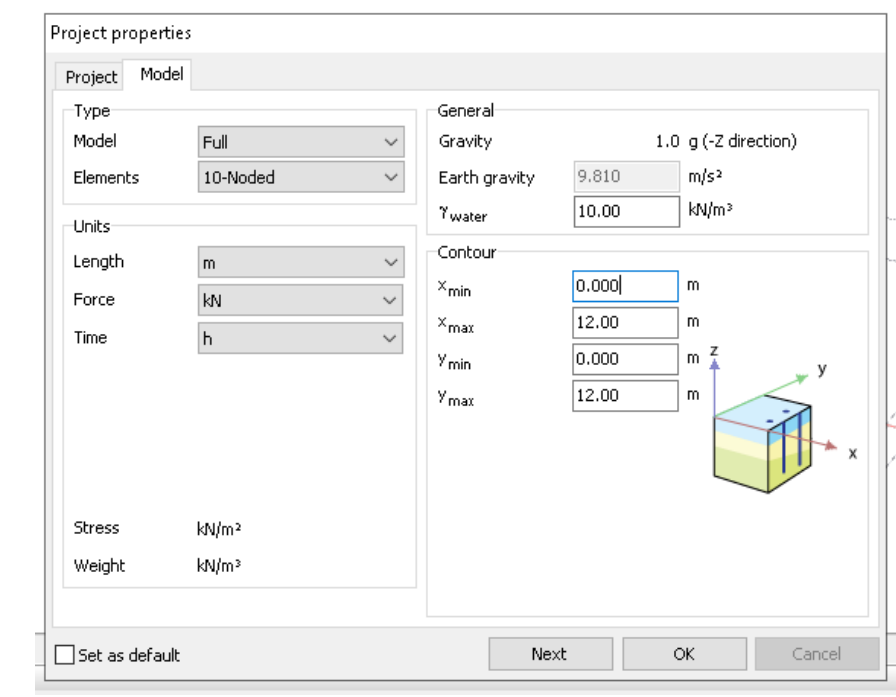

Gambar 4

Project properties yang digunakan pada analisis ini

Tahapan selanjutnya adalah melakukan penggambaran stratifikasi tanah eksisting melalui tools soil pada Plaxis 3D. Pada tahapan ini dilakukan pemodelan lapisan tanah eksisting sesuai dengan data bore hole dari hasil penyelidikan tanah. Selanjutnya dilakukan input material tanah dan bored pile sesuai data sebenarnya.

Tahapan selanjutnya adalah penggunaan tools structure. Pada tahapan ini dilakukan pemodelan bored pile, garis pembebanan, dan elemen interface sebagai pembatas antara material tanah dengan material bored pile (seperti yang ditunjukkan pada Gambar 5) Besar beban yang akan diberikan akan diinput pada tahapan stage contruction.

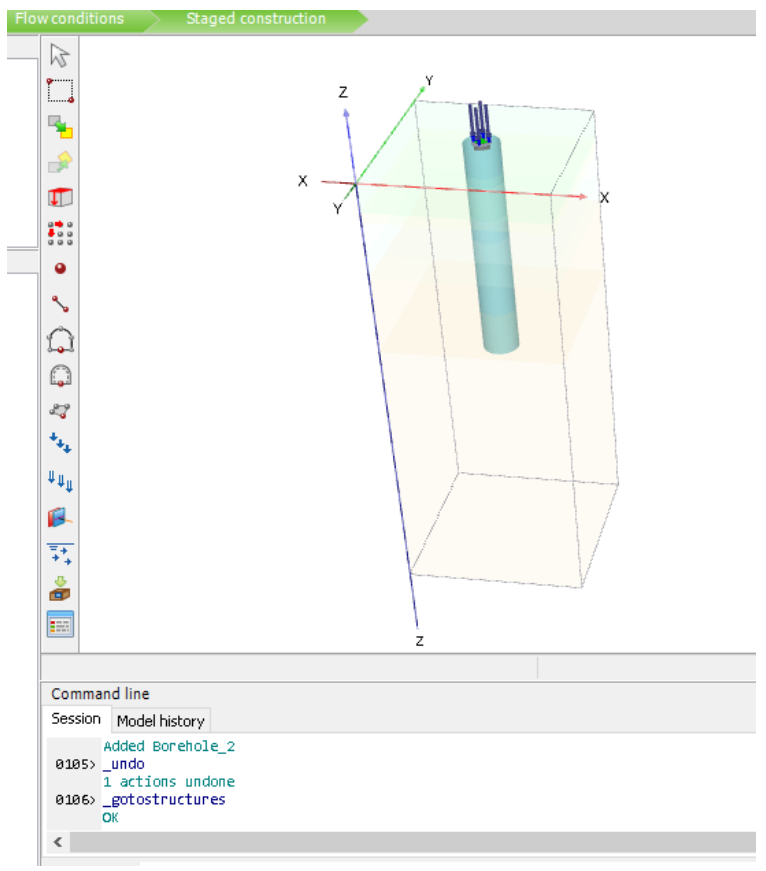

Gambar 5

Hasil pemodelan bored pile, elemen interface dan garis pembebanan 
Analisis Pondasi Bored Pile pada Proyek Jalan Tol Medan-Kualanamu-Tebing dengan Metode Analitis dan Metode Elemen Hingga

Setelah pemodelan tanah dan struktur dilakukan, maka semua item telah selesai dimodelkan. Selanjutnya adalah membagi model tersebut menjadi elemenelemen yang lebih kecil untuk dianalisis dengan menggunakan tools generate mesh. Pada tahapan ini jenis mesh yang dipilih adalah medium sehingga menghasilkan jumlah elemen sebanyak 14717 elemen dan 21494 titik nodal. Adapun hasil generate mesh yang telah dilakukan disajikan pada Gambar 6.

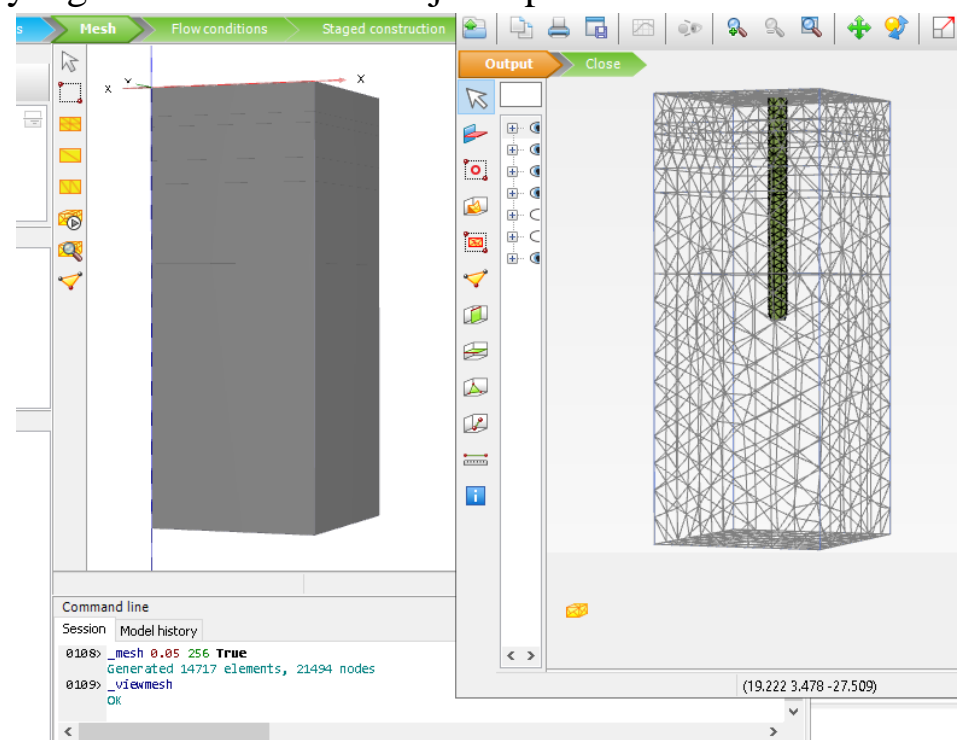

Gambar 6

Hasil generate mesh dengan mesh medium

Setelah struktur terbagi menjadi elemen-elemen. Selanjutnya dilakukan pemodelan tahapan konstruksi dengan tools stage construction sebagai interpretasi konstruksi di lapangan. Konstruksi yang dimodelkan dalam analisis ini adalah proses loading test pada bored pile di lapangan. Pada analisis ini jumlah tahapan konstruksi yang dimodelkan adalah 28 tahapan yang sudah mewakili 4 siklus pembebanan saat loading test dilakukan seperti yang diberikan pada Gambar 7 . Setelah pemodelan tahapan dilakukan, selanjutnya melakukan perhitungan dengan mengaktifikan tools calculate. Maka proses perhitungan di lakukan. 


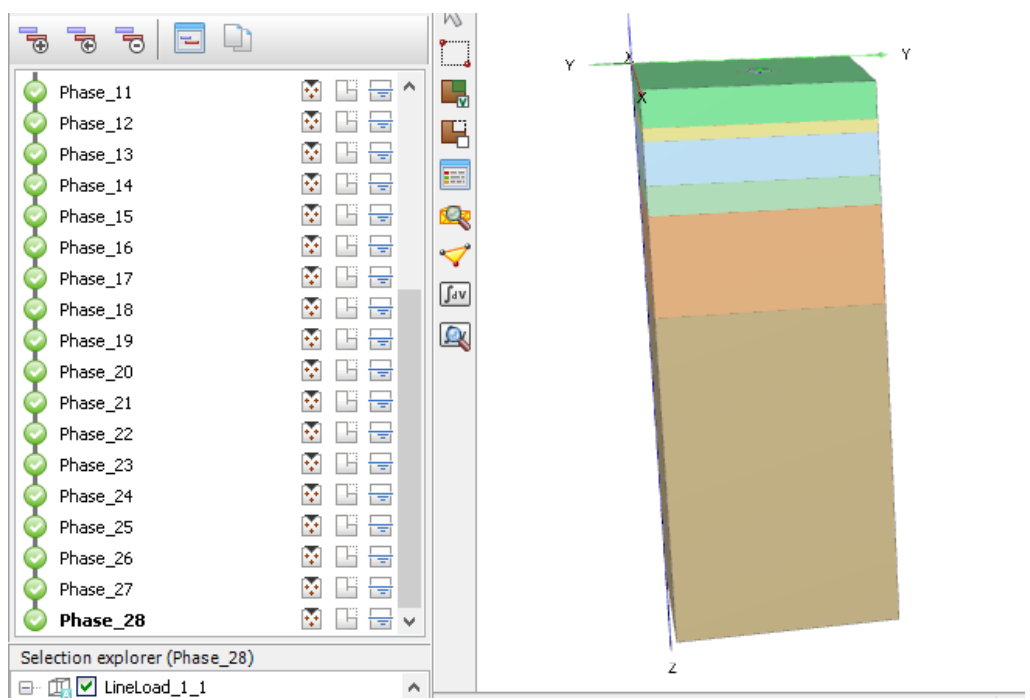

Gambar 7

Pemodelan tahapan konstruksi

Setelah proses perhitungan selesai maka dapat diketahui hasil perhitungan yang telah dilakukan oleh Plaxis. Berdasarkan hasil perhitungan (Gambar 8), besar penurunan yang terjadi adalah $219 \mathrm{~mm}$. Selain itu, Plaxis juga dapat mengeluarkan hasil berupa grafik yang kemudian dapat digunakan untuk menghitung daya dukung bored pile. Grafik hubungan antara beban dan penurunan yang terjadi dari hasil keluaran Plaxis 3D disajikan pada Gambar 8

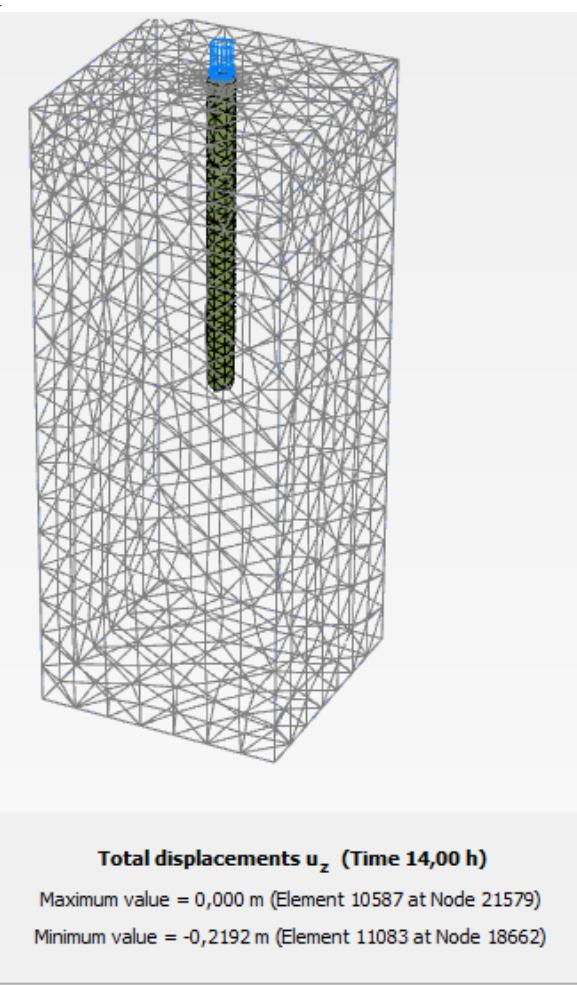

Gambar 8

Penurunan yang terjadi dari hasil perhitungan Plaxis 3D dengan Mesh Medium 
Analisis Pondasi Bored Pile pada Proyek Jalan Tol Medan-Kualanamu-Tebing dengan Metode Analitis dan Metode Elemen Hingga

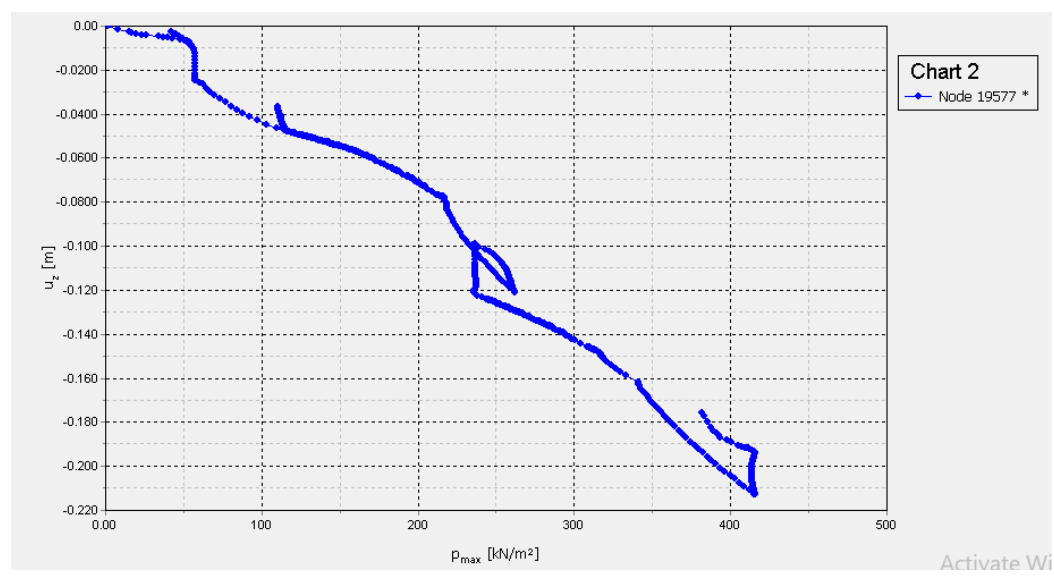

Gambar 9

\section{Grafik Hubungan Beban dan penURUNAn dari Plaxis 3D}

Selanjutnya dilakukan perhitungan daya dukung berdasarkan data penurunan yang dihasilkan oleh analisis Plaxis dengan metode interpretasi Davisson, Chin dan Mazurkiewich seperti pada perhitungan dengan data loading test. Adapun hasil perhitunganya disajikan pada Tabel 8 .

Tabel 8

Daya Dukung Ultimate Bored Pile dari Plaxis 3D Daya Dukung Aksial Bored Pile (ton)

\begin{tabular}{ccc}
\hline $\begin{array}{c}\text { Metode } \\
\text { Davisson }\end{array}$ & Metode Chin & $\begin{array}{c}\text { Metode } \\
\text { Mazurkiewichz }\end{array}$ \\
\hline 155 & 547 & 635 \\
\hline
\end{tabular}

\section{Kesimpulan}

Daya dukung ultimate bored pile tunggal berdasarkan metode analitis dengan persamanaan O'Neil dan Reese 24,6\% lebih besar daripada daya dukung hasil interpretasi loading test dengan metode Davisson, 8,74 \% lebih kecil dari pada metode Chin dan $18,88 \%$ lebih kecil daripada metode Mazurkiewicz. Daya dukung terbesar diperoleh dari interpretasi loading test dengan metode Mazurkiewichz.

Daya dukung dari hasil analisis Plaxis 3D, perbedaan daya dukung tehadap loading test adalah dengan metode Davisson $62 \%$ lebih kecil, dengan metode Chin 2,3\% lebih kecil dan dengan metode Mazurkiewichz 0,8\% lebih besar.

Analisis penurunan bored pile yang paling mendekati nilai sebenarnya dari data loading test adalah perhitungan secara analitis dengan metode penurunan elastis dimana penurunan dari metode elastis 55\% lebih besar daripada penurunan saat loading test. Sedangkan penurunan bored pile dari hasil analisis Plaxis 3D dengan mesh medium $402 \%$ lebih besar dari pada penurunan saat loading test. 


\section{BIBLIOGRAFI}

American Standart Test Method. (2010). Annual Book of ASTM Standart, Section Four Construction, Bar Harbor._Google Scholar

Bowles, J.E. (1997). Analisis dan Desain Pondasi Jilid 2. Jakarta:Erlangga_Google Scholar

Bowles, J.E. (1998). Analisis dan Desain Pondasi, Jilid 2 Edisi Keempat, Jakarta:Erlangga. Google scholar

Broms, B. B. (1964). Lateral Resintance of Piles in Cohesive Soil. Soil Mechanic and Foundation Division Proceeding of the American Society of Civil Engineer,51. Google Scholar

Das, B. M. (1995). Mekanika Tanah 1. Jakarta: Erlangga._Google Scholar

Das, B.M. (1999). Principle of Foundation Engineering, $4^{\text {nd }}$ Edition, PWS - KENT Publishing Company, Boston.Google Scholar

Eid, M., dkk. (2018). Numerical Analysis of Large Diameter Bored Pile Installed in Multi Layered Soil: A Case Study of Damietta Port New Grain Silos Project. International Journal of Current Engineering and Technology. Google Scholar

Fadilah, U. N., dan Tunafiah, H. (2018). Analisa Daya Dukung Pondasi Bored Pile Berdasarkan Data NSPT Menurut Rumus Reese \& Wright dan Penurunan. Jurnal IKRA IHT Teknologi, Vol 2, No, November 2018.Google Scholar

Gultom, C. M. (2019). Perbandingan Analisis Daya Dukung Vertikal Pondasi Bored Pile Berdasarkan Data Pengujian SPT dengan Software Plaxis. Tugas Akhir Mahasiswa USU Google Scholar

Hardyatmo, H.C. (2010). Teknik Pondasi, jilid 1 dan 2, Penerbit Gramedia, Jakarta. Google Scholar

Hardyatmo, H.C. (2010). Mekanika Tanah, jilid 1 dan 2, Penerbit Gramedia, Jakarta_Google Scholar

Harsanto, C., dkk. (2015). “Analisa Daya Dukung Tiang Bor (Bored Pile) pada Struktur Pylon Jembatan Soekarno dengan Plaxis 3D”, Jurnal Ilmiah Media Engineering, Vol.5, No 2, September 2015.Google Scholar

Mansur, S., dkk. (2019). "Analisa Kapasitas Dukung dan Penurunan Tiang Bor Tunggal Akibat Beban Gempa dengan Menggunakan Plaxis 2D", Seminar Nasional Teknologi, Sains dan Hurmaniora 2019.Google Scholar

Nurmaidah. (2017). Studi Analisis Perilaku Daya Dukung Pondasi Tiang Bor dengan Menggunakan Uji Beban Statik dan Model Tanah Mohr Coloumb pada Proyek 
Analisis Pondasi Bored Pile pada Proyek Jalan Tol Medan-Kualanamu-Tebing dengan Metode Analitis dan Metode Elemen Hingga

Paragon Square Tangerang, Banten", Jurnal Education Buliding, Vol 3, No 1, Juni 2017.Google Scholar

Octavia, Riki. (2019). “Analisis Daya Dukung Dan Penurunan Tiang Tekan Hidrolis Square Pile 50x50 $\mathrm{Cm}^{2}$ Pada Proyek Bangunan Bertingkat Di Pluit Jakarta Utara", Tesis, Universitas Sumatera Utara, Medan. Google Scholar

Poulus, H. G. dan Davis, E. H. (1980). Pile Foundation Analysis and Design. John Wiley and Sons, New York. Google Scholar

Prakasa, A. G. dan Rijaluddin, A. (2016). “Analisa Daya Dukung dan Penurunan Pondasi Tiang Bor (Bored Pile) Tunggal dengan Menggunakan Program Plaxis”, Jurnal EEnsitec: Vol 03, No 1, November 2016. Google Scholar

Prakash, S.H., \&Sharma, D. (1990). Pile Foundations In Engineering Practice, John Willey dan Sons, Inc. Canada.Google Scholar

Pratama, R., dkk. (2018). Tinjauan Kapasitas Dukung Pondasi Bored Pile Menggunakan Formula Statis dan Elemen Hingga 2D pada Gedung E Fakultas Teknik Universitas Islam Riau. Jurnal Saintis, Vol 18 No.2, Oktober 2018. Google Scholar

Reese, L. C., dan Wright, S. J. (1977). Drilled Shaft Design and Construction Guidelines Manual, Vol.1 Washington D.C: U.S. Departement of Transportaion.Google Scholar

Sardjono, H. S. (1988). Pondasi Tiang Pancang Jilid 1. Surabaya: Sinar Wijaya. Google Scholar

Sosrodarsono, S., dan Nakazawa. (2005). Mekanika Tanah dan Teknik Pondasi., PT. Pradya Paramita, Jakarta. Google Scholar

Surjandari, N. S. (2008). Studi Perbandingan Perhitungan Daya Dukung Aksial Pondasi Tiang Bor Menggunakan Uji Beban Statik dan Metode Dinamik. Media Teknik Sipil/ Juli 2008/77. Google Scholar

Copyright holder :

Baliaan Muhammad Maulana, Roesyanto, Rudi Iskandar (2021)

First publication right:

Jurnal Syntax Admiration

This article is licensed under:

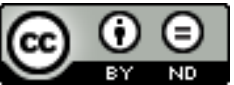

